\title{
A experiência estética na docência: humanescer para a justiça social
}

\author{
Maria Glória Dittrich ${ }^{1}$ \\ https://orcid.org/0000-0003-2107-9005 \\ Vanderléa Meller ${ }^{2}$ \\ https://orcid.org/0000-0002-5342-2659
}

\section{Resumo}

O objetivo do estudo é compreender a experiência estética na docência para o desenvolvimento do humanescer tendo em vista a justiça social. Trata-se de uma pesquisa de abordagem qualitativa, com base no método hermenêutico fenomenológico. Os sujeitos envolvidos foram discentes do curso de Educação Física, licenciatura, da UNIVALI. Este processo é no tempo e no espaço da docência profundamente educativo para o humanescer do discente e do docente, tendo em vista uma formação comprometida com a valorização do respeito e defesa à vida, na complexidade da tessitura do real na cultura contextual. Evidenciamos que na docência as experiências estéticas são fundamentais para promover processos de aprendizagens com desenvolvimento da criatividade do ser humano no seu sentir, pensar, agir e conviver. $\mathrm{Na}$ prática estética os processos sociais e criativos, impulsionaram o ser humano ao sublime no sentido da justiça social, considerando a corresponsabilidade e solidariedade nas relaçóes transdisciplinares de saberes, pessoas, natureza e o transcendente. $\mathrm{O}$ envolvimento na condiçáo de uma docência que prioriza a experiência estética colabora com o humanescer na existência e possibilita a conexão com o eu e com o outro nas aprendizagens e conquistas sociais.

Palavras-chave: Humanescer, Experiência estética, Docência.

\section{A esthetic experience in teaching: humanescing for social justice}

\section{Abstract}

The objective of the study is to understand the aesthetic experience in teaching for the development of human being in view of social justice. This is a qualitative research based on the phenomenological hermeneutic method. The subjects involved were students of the Physical Education course, degree, from UNIVALI. This process takes place in the time and space of teaching that is profoundly educational for the human being of the student and the teacher, with a view to training committed to valuing respect and defending life, in the complexity of the fabric of reality in contextual culture. We show that in teaching, aesthetic

\footnotetext{
${ }^{1}$ Doutora em Teologia - EST, Mestre em Educação - FURB e Bacharel em Filosofia - FEB. Professora da Universidade do Vale do Itajaí - UNIVALI - gloria.dittrich@univali.br.

${ }^{2}$ Doutora em Educação pela Universidade do Vale de Itajaí - UNIVALI. Professora na Universidade do Vale de Itajaí - UNIVALI - vanderlea@univali.br.
} 
experiences are fundamental to promote learning processes with the development of human beings' creativity in their feeling, thinking, acting and living together. In aesthetic practice, social and creative processes have propelled the human being to the sublime in the sense of social justice, considering co-responsibility and solidarity in the transdisciplinary relations of knowledge, people, nature and the transcendent The involvement in the condition of teaching that prioritizes aesthetic experience collaborates with the humanescer in existence and enables the connection with the self and with the other in learning and social achievements.

Keywords: Humanescer, Aesthetic experience, Teaching.

\section{Introduçáo}

Como pensar a formação docente na universidade sem acolher um sentimento de encantamento para com a vida que nos convoca a olhar, sentir, saber pensar e conviver dentro dos diferentes saberes e maneiras de ser da pessoa?

Um processo de descobertas nos convoca aos propósitos da formação docente que está envolvida em uma reversibilidade da ação interativa e intercomunicativa, do eu-docente que expande a sua consciência e ressoa no outro-docente em suas dinâmicas de atividades na docência. Esta é uma dinâmica que se tece na feitura de uma rede com tramas vivas de diversas pessoas, entre elas também os discentes que são professores em formação. Este processo gera uma sinergia que atravessa a corporeidade do docente, no seu ser-estar-fazer-conviver, atuando educativamente na escola e na sociedade. Com efeito, esse fenômeno real possibilita a educação como princípio de justiça social.

Quando pensamos sobre justiça social remetemos à necessidade de uma maneira de ser da pessoa na educaçáo que implica respeito, solidariedade e corresponsabilidade para com a vida, no amplo tecido social, nos ideais de igualdade e equidade, nas oportunidades para ela educar-se, tendo em vista desenvolver-se com capacidade de realizar-se e contribuir para o bem viver com autenticidade, priorizando o que é justo e verdadeiro. Para Aristóteles (1996) a justiça está relacionada com a qualidade de ser da pessoa no sentido de respeitar as diferenças e escolher aquilo que é justo nas relaçóes entre as partes envolvidas. Para ele, essa era uma postura de dignidade e virtude de ser no mundo, agindo com sabedoria e retidão no pensar e viver as experiências no mundo.

Dentro desta visão, a formação docente implica uma maneira de ser na docência, carregada de senso de justiça para conduzir propósitos e ações que demandam esforços de princípios éticos, de justeza e lisura, no comprometimento e corresponsabilidade para com a vida. Neste contexto, as 
pessoas vão se educando e alargando suas consciências, dentro de abordagens de conhecimentos com metodologias que devem priorizar o despertar da criatividade, que permitem empreender ideias e processos que envolvem a integraçáo e o cuidado humano, com responsabilidade educacional, social e cultural no âmbito do ensino, pesquisa e extensão, em conexão, tendo como telos o bem comum. Para Morin (2000, p. 55),

A complexidade humana não poderia ser compreendida dissociada dos elementos que a constituem: todo desenvolvimento verdadeiramente humano significa o desenvolvimento conjunto das autonomias individuais, das participaçóes comunitárias e do sentimento de pertencer à espécie humana.

Torna-se fundamental desconstruir modelos de heranças funcionais que ainda perduram nos processos escolares institucionalizados, os quais exerceram poucas açóes e preocupaçóes em torno da visão ampliada e complexa do pensamento humano, nas relaçóes no/do mundo e na dinâmica de humanescer. Para Dittrich (2016), principalmente em torno da formação universitária, é preciso resgatar a credibilidade da ciência e do encantamento com os diversos saberes, entre eles o da experiência estética, como a sensibilidade e inteligibilidade na beleza de descobrir as verdades que promovem aberturas para um bem viver, com dignidade e qualidade de felicidade, no viver social compartilhado saudavelmente com paz e justiça

Para Hermann (2018, p. 12) na educação "[...] como uma autocriação de si mesmo, a contribuição da estética assume um lócus significativo, porque é mobilizando a dimensão corporal do autoconhecimento que podemos nos compreender e aprender a lidar com nossos afetos." Destacamos que, também precisamos entender que nos processos de educação na docência compartilhada, na experiência estética, nossa forma de sentir-pensar-agirconviver emerge dos processos vitais-cognitivos da emoção-razão indissociavelmente.

A experiência estética na docência necessita ser oportunizada, pois a lógica das estruturas curriculares e didáticas foram tradicionalmente organizadas nos fundamentos conteudistas e disciplinares, na perspectiva disciplinadora, em modelos de pensamento e de ação ideologicamente fechados, que muito valorizaram a racionalidade técnico-instrumental ou ideológico-social. Uma perspectiva que não contemplou as múltiplas dimensóes do ser humano nas suas inter-trans-relaçóes com o outro, com a 
natureza e com o sagrado que se manifesta em diferentes linguagens simbólicas.

O ser humano, sujeito das experiências e aprendizagens, foi muito negligenciado ao não ser considerando na sua integralidade multidimensional, na sua capacidade de criatividade, pois, limitadamente, foi colocado como aquele que precisa ser moldado e domesticado. Este foi um modelo proposto dentro de saberes que nem sempre apontaram para a formação de seres humanos livres para criar sua autossustentação, que empreende ideias e trabalhos com uma postura de respeito, amorosidade e corresponsabilidade para com a vida.

$\mathrm{Na}$ experiência estética na docência a dinâmica criativa da formação do pensar-criar-fazer-conviver indica uma forma dialógica de linguagens e conversações entre os saberes, métodos e pessoas, logo, necessita com urgência humanescer para o reencantamento no aprender a aprender, tendo em vista uma docência libertadora e criativa. Para Dittrich e Ramos (2017, p. 114) "O humanescer implica um processo de saber cuidar do ser humano no ensino-aprendizagem numa perspectiva integral e multidimensional na formação universitária”. Para este propósito expressamos uma concepção de educação que valoriza a experiência estética como manifestação da percepção do ser humano, no desenvolvimento da capacidade criativa e de autoorganização reflexiva nas inter-trans-relaçóes, dentro de uma cultura multidiversa.

Para Hermann (2005, p. 44), a

[...] experiência estética produz uma oposição ao mundo cotidiano, seu êxito estaria na possibilidade de vivenciar o singular como contraponto à trivialização da vida e da rigidez de princípios éticos abstratos que, totalmente desencarnados, distanciam-se sempre mais do mundo da vida. Assim, a experiência estética dirige nossa atenção para o inesperado, àquilo que é diferente de nós e traz também a promessa de uma reconciliação não forçada do particular com o universal, abrindo um espaço de experiência que não pode ser dado pela justificaçáo racional.

A fim de ampliar espaços e tempos na dinâmica da consciência na docência, do ser docente, torna-se necessário revisar a trajetória de experiências que guarda memórias em territórios corporalizados, na sua estrutura e organização, que muitas vezes foram limitados e ilimitados, inclusivos e excludentes nas formas de conduzir transdisciplinarmente os 
saberes específicos e suas interligaçóes com o todo dos fenômenos do real vivido.

A abertura possibilita entender as ambiguidades e polaridades que existem entre os saberes conceituais e técnicos, que se traduzem em linguagens carregadas de símbolos e signos com seus contextos de significados, é um desafio na experiência estética educativa. Percebemos que tal ideia aponta para um olhar docente capaz construir diálogos criativos e ecoformativos, que oportunizam aprendizagens e que favorecem a intervenção adequada no campo educativo. É momento de revisar as escolhas conceituais e atitudes na conquista de saberes e práticas coerentes com as finalidades da educaçáo criativa e crítica, favorecendo o humanescer com encanto no aprender, com significados para a vida, ou seja, aqueles que acolhem as necessidades humanas, principalmente as convergentes à justiça social.

As propostas presentes nas intervenções foram realizadas em ambientes que evidenciaram a pluralidade cultural, como na aldeia indígena e instituições sócio educativas. As práticas foram envolvidas na teia complexa do conhecimento, presente em diferentes áreas, e nos entendimentos que evidenciam processos e evoluçóes na organização do conhecimento. Neste contexto, o objetivo deste estudo busca compreender a experiência estética na docência para o desenvolvimento do humanescer tendo em vista a justiça social.

\section{O caminho percorrido}

O estudo caracteriza-se como uma pesquisa de abordagem qualitativa, na perspectiva do método da hermenêutica fenomenológica. Expressa propostas educativas realizadas no âmbito da formação docente universitária que envolveram pesquisa e extensão, e integraram 20 discentes do Cursos de Educação Física, licenciatura, da UNIVALI. Os dados foram coletados a partir dos planejamentos dos discentes e os relatórios desenvolvidos pelos discentes envolvidos e que expressaram as experiências e percepçóes pessoais, em torno das práticas e temáticas envolvidas com foco no humanescer na educação.

Os encontros ocorreram semanalmente e foram promovidos estudos textuais, diálogos reflexivos, atividades práticas no campo de atuação e saídas de campo na Aldeia Indígena M"Biguaçu, no município de Biguaçu, no estado de Santa Catarina; também na instituição Lar Fabiano de Cristo do município de Itajaí. As propostas envolveram diferentes práticas corporais e 
linguagens culturais da arte, musicalidade, a leitura, práticas corporais e a expressão textual. Cada discente teve a oportunidade de expressar suas percepçóes, a partir dos conhecimentos teóricos e práticos em diferentes manifestaçóes culturais e experiências vividas.

\section{Experiência estética - olhares no processo de humanescer}

A perspectiva da construção do conhecimento, proposta na formação docente, integra a experiência estética como um movimento dinâmico do humano envolto pelos sentidos nas percepçóes dos fenômenos. Buscamos impactar o sentir-pensar com um olhar mais atento para o mundo e ao ser humano incluído nele, com afetividade, empatia e solidariedade. Os fenômenos nem sempre são familiares, muitas vezes nos causam estranhamento, entre eles as questôes da justiça social e educação.

A experiência estética também causa uma espécie de dor, na medida em que deixa emergir a estranheza, a resistência, a adversidade das coisas, e é justamente pelo impacto que nos chega pelos sentidos que nossos afetos podem ser mobilizados, constituindo-se nisso a possibilidade de rever nossas crenças, de conhecer como as paixóes agem sobre nós e de aprimorar nossa sensibilidade ética. (HERMANN, 2018, p. 13).

O exercício de contato e estesia esteve envolvido em um olhar para si e para o outro no mundo, para isso buscamos a aproximação com a diversidade cultural, social e psicológica. Percorremos as diferentes instituiçôes na busca de um contato dialógico e real, identificando os conhecimentos e estruturas inerentes à constituição e aos sujeitos presentes. Foi a aproximação que nos causou envolvimento e reconhecimento da realidade, da energia presente e expressividade. Percorrer os ambientes por meio de atividades da extensão, ensino e pesquisa foi um ato de presença em que muitas experiências estéticas foram despertadas para a docência.

A atuação dos discentes na aldeia indígena M"Biguaçu, na função de docentes em formação envolvida nos estágios e projetos de pesquisa, possibilitou a identificação da pluralidade cultural, que está viva e se relaciona com o passado e futuro, apresentando uma educaçáo que transpóe o tempo e culturas. A postura reflexiva em torno das condiçôes sociais, políticas e econômicas do povo indígena foi possível a partir da percepção da realidade. Para Franco (2012) a própria identidade étnica necessita ser pensada como 
forma coletiva de autocompreensão, evidenciada nas relaçóes sociais. O multiculturalismo vem pautando a sobrevivência física, cultural e a dignidade indígena, em seus costumes, terras e os recursos naturais, porém a cidadania envolve a aquisição de igualdade de condiçôes em relação aos demais cidadãos brasileiros. O povo indígena vem sofrendo influências do mito do desenvolvimento e as pressóes de padronização cultural e econômica, em um processo político de dominação decorrente da imposição do etnocentrismo ocidental ao mundo.

A sensibilização com a diversidade na origem de nossa história, das condiçốes sociais e das relaçóes ecológicas do indígena despertou a percepção integradora cidadã e ambiental. Um envolvimento com hábitos $\mathrm{e}$ comportamentos de um povo, em seus modos de vida possibilitou enxergar o ser de direitos, o respeito às diferenças e valores presentes. $\mathrm{O}$ pensamento social sobre as questôes étnicas e raciais foram compartilhadas com perspectivas inclusivas e sustentáveis. Foi ao redor de uma fogueira (Fig. 1) que dialogamos, um lugar e organização que instigou a ver e sentir a educação em conexão com o humano e sua ecologia.

Fig. 1: Diálogos sobre a cultura indígena na aldeia indígena.

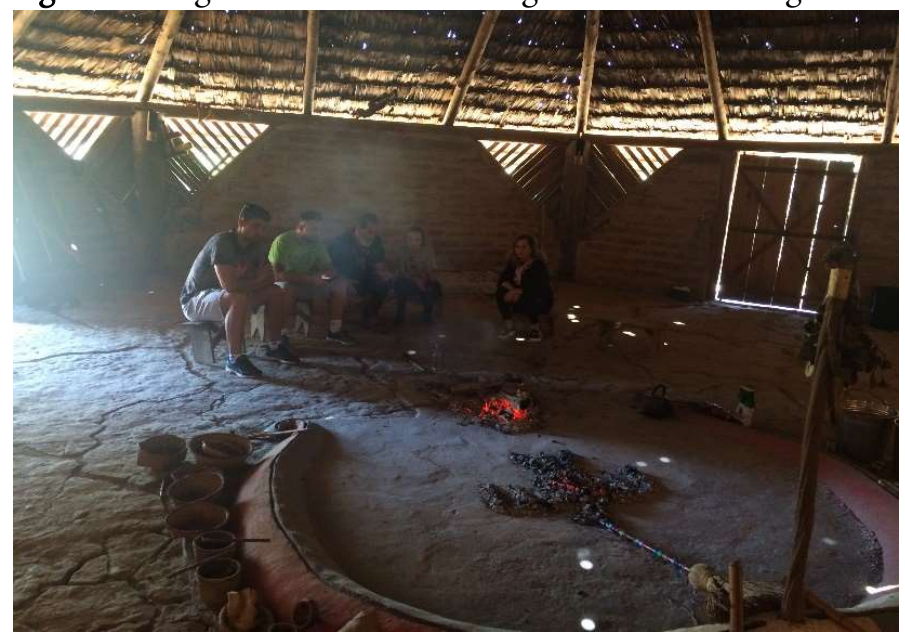

Fonte: Arquivo das pesquisadoras.

As noçóes de tempo foram revisadas, fora das determinaçóes cronológicas do relógio - Chronos, pois na ligação com a natureza o tempo é da duração da consciência que quer humanescer existencialmente. Para Dittrich e Ramos (2017, p. 115) "Na filosofia grega Kayrós significava o 
tempo certo de se viver algo, na busca da verdade sobre o real vivido". Um mundo vivido com mais autonomia temporal que permite a dedicação necessária para interagir no interior de culturas no sentido de aprender a aprender com o novo, o outro e os sinais que vem de uma psicoesfera social e ecológica que clama por explicação e representação, tocando o sensível e o inteligível do humano. Com efeito, essa foi uma vivência de aprendizagem estética.

Para Maturana e Varela (2001, p. 31): "Essa Circularidade, esse encadeamento entre ação e experiência, essa inseparabilidade entre ser de uma maneira particular e como o mundo nos parece ser, nos diz que todo ato de conhecer faz surgir um mundo". Nas trilhas ecológicas, entre árvores e animais, com pessoas indígenas e professores da aldeia e discentes tiveram oportunidades de serem observadores. Ao observar perceberam-se e envolveram-se na circularidade, se enxergando como parte do fenômeno, despertando para estranhamentos e entendimentos, pois " [...] quando examinarmos mais de perto como chegamos a conhecer esse mundo, descobriremos sempre que não podemos separar nossa história das açóes biológicas e sociais - a partir das quais ele aparece para nós" (MATURANA; VARELA, 2001, p. 28).

A cultura indígena trouxe ligações fundantes do humano, porém sabemos o quanto nos distanciamos das origens constituintes e que muito desfavorecem o processo da experiência estética para humanescer. Acolher o outro em sua cultura e diversidade instigou o olhar estético para humanescer no caminhar juntos, sentir a energia da natureza, das crenças, das cantigas que clamam pela vida em diferentes origens, vegetais, animais, minerais e humanas, especialmente dos recursos didáticos carregados de arte e natureza que lá encontramos. Os bambus, cabaças, madeiras que se transformam em instrumentos musicais, em utensílios e brinquedos, que muito contribuíram com a expressão em diferentes linguagens e a interligação das habilidades humanas que fomentaram relaçóes ecoformativas. A história do povo indígena nos apresentou uma realidade de luta pela preservação

Nas percepçóes dos discentes " $A$ cultura indígena nos reapresentou a natureza, com os indios e com os demais acadêmicos trouxe para nós inúmeras experiências sobre a sensibilidade com o outro e com as coisas de uma forma mais afetiva de aprender no lugar que estamos, com o vivido". (Discente 5). O contato com a cultura indígena instigou relaçóes de aproximação amorosa com o meio ambiente e princípios culturais, despertando para visão ecológica e grande responsabilidade com a justiça social, no que diz respeito à dignidade da vida manifesta de muitas formas, como também um despertar estético para a 
solidariedade do ser, no tempo e no espaço. Para Maturana e Varela (2001, p. 269), o ser humano está mobilizado na biologia do amor, "[...] a aceitação do outro junto a nós na convivência, é o fundamento biológico do fenômeno social para a educação. Sem amor, sem aceitação do outro junto a nós, não há socialização, e sem esta não há humanidade”.

Reconhecer o ambiente indígena na convivência, em seu modo de viver e características de organização social e educativa, foi uma ação interativa com o povo indígena e exercício de alteridade que implica no humanescer da consciência que acolhe o outro na sua diversidade, mas com direito de defesa a vida para o bem viver. Encontramos um fluxo transdisciplinar muito intenso com atividades envolvendo o diálogo sobre a realidade vivida e relações sociais na preservação cultural, pois é um exercício de respeito e reconhecimento constante. O brincar na comunidade e na escola favoreceram práticas educativas consolidadas em torno das manifestaçóes indígenas artísticas e corporais com interação social. Com o instrumento musical construído com bambu, o "Pau de chuva", nos conectamos ao som da natureza e nos envolvemos em um ritmo de conexão que instigou a ecoformação, "[...] como uma maneira sintética, integradora e sustentável de entender a ação formativa, sempre em relação ao sujeito, à sociedade e à natureza. $\mathrm{O}$ caráter de sustentabilidade somente é possível quando estabelecem relaçóes entre todos os elementos humanos (TORRE, 2008, p. 21).

A experiência estética na docência possibilita a manifestação do ser humano perceptivo no mundo que, seguro pelas compreensões já estabelecidas, expande para fora de si e, na continuidade, volta-se novamente para si, na dinâmica da complexidade e transcende em seu entendimento sobre as experiências vividas. Esta dinâmica permite um exercício corporal sensívelcognitivo do ser humano, de forma a atravessar os âmbitos sociais e culturais e possibilitar novas compreensóes. Tais experiências estéticas, no contato social, envolveram o humanescer na abertura de consciência para o entendimento das condiçóes humanas, seus papéis e condiçóes sociais em busca de relaçóes com equidade.

Humanescer é um fenômeno humano que faz a pessoa sentir o amor incondicional à vida, que se manifesta misteriosamente no ato educativo do encontro com o outro, com a cultura na sociedade e com a natureza, onde ocorrem processos criativos de ensinar e aprender com significado para a vida e que se dinamiza criativamente. (DITTRICH; RAMOS, 2017, p. 116-117). 
As diversas práticas vivenciadas foram estruturadas em dinâmicas transdisciplinares que mobilizaram capacidades sociais, cognitivas, físicas, psicológicas e espirituais, envolvidas em diferentes linguagens, por meio da observação, leitura, interpretação, expressão, intervenção e construção de objetos didáticos. As açóes educativas e a busca do entendimento das percepçóes integraram saberes críticos e criativos, em processos que valorizaram os sujeitos que aprenderam a conhecer os seus próprios processos de aprender a aprender, percebendo-se como centro da intencionalidade na trama interconectada das áreas de atuação, dos conhecimentos e dos sujeitos no contexto.

A Declaração de Jomtien (UNESCO, 1990) define que todas as pessoas devem estar em condiçóes de aproveitar as oportunidades educativas que satisfazem suas necessidades básicas de aprendizagem, sendo que esse processo deve ocorrer com a responsabilidade de respeitar e desenvolver a herança social, cultural, linguística e espiritual. Com efeito, o processo se faz , protegendo e promovendo relaçóes de amorosidade com os saberes que emergem do encontro de pertencimento entre os seres humanos, a cultura, a natureza e o desejo de transcendência pessoal e coletivo, envolvido em valores humanistas e nos direitos-deveres ao cuidado à vida, no trabalho pela paz e solidariedade internacional .

As aprendizagens desenvolvidas na perspectiva da inter-trans-relaçóes envolvem bases transdisciplinares e ecossistêmicas que integram o ser humano estético, pois a organização do conhecimento é um movimento de integração do sensível-inteligível possibilitando o humanescer. Tais açôes geram impactos e consolidam propostas que são culturalmente estabelecidas, portanto os momentos reflexivos fazem parte do agir criativo e crítico.

A Lei de Diretrizes e Bases da Educação Nacional (LDBN) 9394/96, no Art. $1^{\circ}$, define que "A educação abrange os processos formativos que se desenvolvem na vida familiar, na convivência humana, no trabalho, nas instituições de ensino e pesquisa, nos movimentos sociais e organizaçóes da sociedade civil e nas manifestaçóes culturais". A visão abrangente de educação se consolida nos diferentes ambientes e açôes formativas que são desenvolvidas, com propósitos ampliados de ser humano e sociedade, que se complementam e definem a formação em consonância com as experiências vividas e no humanescer.

As propostas da formaçáo educativa para a docência na Universidade, que valorizamos, busca promover a experiência estética em prol do humanescer para a justiça social. Nas políticas de educação e nas açóes didáticas, a docência está envolvida em desafios, perante a complexidade que 
compóe o pensamento e a necessidade da visão, que integra a organização do conhecimento e atuação na educação nos caminhos de tessituras do ser, do saber, do fazer e viver do ser humano.

A educação universitária, para formação docente, está proposta na Resolução CNE/CP No 2/2019, a qual define as Diretrizes Curriculares Nacionais para a Formação Inicial de Professores para a Educação Básica e, no Art. $8^{\circ}$, estabelece que os cursos destinados à formação devem ter fundamentos pedagógicos, entre eles: - compromisso com a educação integral dos discentes em formação, visando a constituição de conhecimentos, de competências, de habilidades, de valores e de formas de conduta que respeitem e valorizem a diversidade, os direitos humanos, a democracia e a pluralidade de ideias e de concepçóes pedagógicas.

A conquista de uma perspectiva abrangente e integradora de educação é possível quando as propostas estão focadas na amplitude do potencial estético humano e no envolvimento abrangente das dimensóes humanas. Buscamos promover experiências estéticas que possibilitam as manifestações das percepçóes do ser humano sensível-inteligível, que é livre e criativo. A estética proposta por Baumgarten (1993) do grego aisthésis (sensibilidade), requer um "conhecimento sensível" que na experiência favorece a ampliação da percepção humana sobre os fenômenos do real

O humanescer na docência, tendo em vista a formação do ser humano para a justiça social, exige maior atenção e estímulo ao desenvolvimento do ser estético, no sentido de estimular a promoção de experiências didáticopedagógicas que oportunizam atividades criativas para a abertura da imaginação criadora, espontânea e em busca de sentido do conhecimento na aprendizagem. Isto é perceber um envolvimento estético com o sublime, que é aquilo que sentimos como encantamento de nossa ambiguidade finitude e infinitude para ser mais o que somos. Para Schiller (2005, p. 6) o sublime no campo da estética é

Um objeto cuja representação faz a nossa natureza sensível sentir os seus limites, a nossa natureza racional, entretanto, a sua superioridade, a sua liberdade em face da sensibilidade. Fisicamente, portanto, rebaixamo-nos, mas moralmente, isto é, mediante ideias, elevamo-nos.

Uma elevação que possibilita a potencialização da experiência estética. Para Kant (2005) a vivência da atividade estética está ligada ao movimento criativo da consciência do ser humano, marcadamente no movimento de sua subjetividade que traz representaçóes das sínteses com seu objeto. Com efeito, 
na estrutura de tempo e espaço da razão pura e prática do ser criador, do sujeito. O ser estético não é qualidade do objeto, mas o afetamento intuitivo do sujeito na síntese interativa com o objeto, ou seja, o modo da intuição pura, original de como ele foi afetado. Esta é a dimensão subjetiva da experiência estética, um movimento em seu sentimento vital (Lebensgefühl), na apreensão ou contemplação sublime de um objeto, tendo em vista o impulso intuitivo para o prazer de desvelar uma grandeza infinita dada na experiência estética. (KANT, 2002).

Os afetamentos em prol dos sentimentos vitais integram o humanescer no processo da docência, no sentido de deixar cada pessoa nascer nas práticas com suas representaçôes sensíveis e inteligíveis, carregadas de diferentes compreensôes sobre um determinado objeto de aprendizagem. (DITTRICH, URIARTE NETO, 2016). Destacamos a experiência estética, no foco das humanidades, como uma dimensão carente de reflexôes e consolidação perante os princípios da formação que, crescentemente, vem sendo integrada nos discursos das Leis, Diretrizes e Políticas Públicas educacionais e, em especial, de Formação de Professores. As ações voltadas à valorização do humanescer na educação necessitam conceber oportunidades de acesso e aprendizagens que garantam a justiça social para a integralidade e equidade humana. Uma construção do conhecimento com evolução da emancipação cidadã e científica, permeada por princípios estéticos, éticos e críticos em torno das experiências e do conhecimento.

Para Moraes (2016) a cidadania planetária emerge na consciência que reconhece que todos habitamos um mesmo planeta e que precisa ser cuidado, reconhecido, valorizado e amado, portanto, é necessário acordar valores e atitudes comuns a fim de enfrentar a crise sistêmica que afeta a sobrevivência de nossa civilização. Neste contexto, a cidadania constitui a razão de ser da civilidade compartilhando um ideal de justiça com compromissos com a vida coletiva no planeta. Uma política do humano para solidarizar o planeta e reduzir as injustiças sociais em todos os aspectos da existência humana, resguardando os bens planetários, como a água, a qualidade do ar que respiramos, entre outros.

A fim de promover experiências estéticas, muitos ambientes, temáticas e recursos foram socializados e explorados nas entidades socioeducativas, escolas, museus, educação indígena, entre outros, evidenciando as perspectivas da fenomenologia de Merleau-Ponty (1999, p. 18),

O mundo fenomenológico é não o ser puro, mas o sentido que transparece na intersecção de minhas experiências, e na intersecçấo de 
minhas experiências com aquelas do outro, pela engrenagem de umas nas outras; ele é, portanto, inseparável da subjetividade e da intersubjetividade que formam sua unidade pela retomada de minhas experiências passadas em minhas experiências presentes, da experiência do outro na minha.

A experiência estética envolve "a experiência do outro na minha" como engendramento da justiça social, que é solidária e co-responsável para com a vida, na direção do bem viver com paz e prosperidade. Não há oposição entre o objetivo e subjetivo, o conhecimento é construído a partir dos fenômenos e dos significados, empregando o sentido que emerge na consciência do ser do conhecimento, construído na relaçáo do eu com o outro e o ambiente.

$\mathrm{Na}$ perspectiva da formação docente e humana, mais ampliada e interconectada, que valoriza os saberes estéticos temos "[...] a tarefa de sensibilizar e desenvolver os sentidos, fazendo-se acompanhar de uma visão criticamente filosófica de seu papel na obtenção do saber, compete prioritariamente aos nossos cursos de formação de professores, às licenciaturas [...]" (DUARTE JÚNIOR, 2000, p.213). Esta proposta envolve a seleção de unidades temáticas e metodologias coerentes com as capacidades $\mathrm{e}$ necessidades do ser humano em seu pensamento complexo e na sociedade. $\mathrm{Na}$ tríade, proposta por Morin (2000), indivíduo/sociedade/espécie as pessoas são produtos do processo reprodutor da espécie humana e nas interaçôes elas produzem a sociedade, a qual testemunha o surgimento da cultura, e esse movimento retroage sobre as pessoas pela cultura. Neste foco, a docência tem uma ligação direta com essa tríade proposta, pois formas de ser do docente e suas representaçóes de linguagens, crenças, valores, princípios de pensamento e de ação são tramados na tessitura complexa da cultura na sociedade.

$\mathrm{O}$ que exprimimos surge no reapoderar-se de nossos desejos e necessidades no aprender a aprender existencialmente, a fim de compreender o que sentimos, vemos, pensamos e como agimos na convivência. Este processo pode ser entendido como aprendizagem, pois é uma "tradução/reconstrução/autoeco-organização do sujeito, em interação ecológica com seres vivos, culturas, informação, energia e matéria, potencialmente mediada pelo docente, pelos livros, pelos pares, pela vida". (SUANNO; MORAES, 2017, p. 76)

$\mathrm{Na}$ experiência estética, no processo da docência, a aprendizagem vai ocorrendo nas aberturas das provocaçóes, estímulos e perturbaçóes do mundo. Para Merleau-Ponty (1999, p.4), "Retornar às coisas mesmas é retornar a este mundo anterior ao conhecimento do qual o conhecimento 
sempre fala, e em relação ao qual toda determinação científica é abstrata, significativa e dependente [...]” A construção do saber científico necessita voltar às coisas mesmas para ser autêntico, pois verdadeiro é ser fiel ao que se mostra e compatível aos princípios da justiça social.

A experiência estética é dinâmica criativa na formação do pensar crítico, na manifestação da criatividade da pessoa, na auto-organização do seu pensarsentir-agir- conviver reflexivo, respeitoso, amoroso e aberto às novas ideias, para novos processos de construçáo do conhecimento, amplamente vinculado ao humanescer. Os processos criativos e de compreensão dos fenômenos e conceitos necessitam de sensibilidade humana, abertura da imaginação criadora para um viver solidário, inclusivo, diverso e flexível, no exercício da ética da vida, em um contexto democrático que respeita e pratica a justiça social, com o equilíbrio da liberdade de expressão na coletividade atrelada à cultura.

Nas atuações realizadas nas instituições socioeducativas a condições de vulnerabilidade social do ser humano foram muito evidenciadas, portanto a busca foi por meio da arte, da educação e da saúde elevar as condições de vida dos sujeitos. Dialogar sobre a vida e suas condições foi uma temática fundamental, envolveu o enfretamento de barreiras e a tomada de consciência para a busca e encontro dos propósitos existenciais de cada envolvido. $\mathrm{Na}$ interligação com o meio ambiente, já reconhecido pelos discentes, o cultivo da terra foi uma maneira de garantir aos educandos da instituição o alimento diário, por meio da horta preparada no terreno local, com princípios ecológicos e transdisciplinares. Em formato de mandala e com recursos naturais, biodegradáveis e reutilizáveis foi possível criar uma consciência sustentável e contribuir com a saúde. A experiência estética no contato com a natureza foi fundamental para ativar o humanescer, pois o envolvimento promoveu o plantar, cuidar e colher o próprio alimento, na perspectiva da sustentabilidade.

No cultivar coletivo, dos sujeitos integrados em relações de cuidado, ocorreu a consolidação das práticas de extensão e pesquisa nos princípios da justiça social e para sujeitos solidários, reflexivos e críticos, amparados por princípios da ética, sendo revisados na construção cultural, em que as experiências estéticas estão envolvidas. Para Duarte Junior (2000, p.179) ocorre a "[...] necessidade de um equilíbrio entre o universal e o particular, entre a cultura humana como um todo e aquela cultura específica na qual nascemos e fomos criados. Verdades abstratas e verdades encarnadas, situadas”. Os valores que empregamos aos dados, na intencionalidade da efetivação das ações sociais sustentáveis, tornam-se fundamentais para a 
compreensão e reflexôes coerentes com a realidade e princípios de cuidado à vida.

As práticas investigativas e sociais permitiram a sensibilidade no olhar atento, com escuta e expressôes em diferentes linguagens fortalecendo uma dinâmica de saberes para o autocuidado e relaçóes positivas, pois "O corpo não suporta carregar o peso de um conhecimento morto que ele não consegue integrar com a vida" (ALVES, 1994, p.19). Na multidimensionalidade do ser humano, na sua dynamis da vida, constituintes dos processos vitais e cognitivos de sua corporeidade foram envolvidas as experiências vividas nas formaçóes educativas e processos investigatórios. Foram empreendidos esforços para promover o olhar estético na educação, com respeito às dificuldades e diversidades. Para Morin (2000, p. 55) "É a unidade humana que traz em si os princípios de suas múltiplas diversidades. Compreender o humano é compreender sua unidade na diversidade, sua diversidade na unidade. É preciso conceber a unidade do múltiplo, a multiplicidade do uno".

$\mathrm{O}$ contexto da pluralidade e da intersubjetividade são fundamentos da experiência estética, são os sentimentos em comum que postulam a intersubjetividade do gosto e do prazer/desprazer. Os consentimentos universais não significam um poder de mudanças do outro, mas para que o diálogo ocorra, respeitando os diferentes pontos de vista, porém que o direito à vida, respeito à dignidade humana e ao âmbito ecoformativo sempre esteja garantido. Desejar e reivindicar o consentimento dos outros no compartilhamento da justiça social não é um processo autoritário, é uma maneira de estabelecer comunicação crítica e criativa que busca refletir sobre "uma policrise de dimensóes planetárias, [...] triunfo da tecnologia e da ciência em detrimento do lado humano da humanidade e das relaçóes entre os diversos elementos constitutivos do triângulo da vida (indivíduo/sociedade/natureza)" (MORAES, 2015, p. 14-15).

A revisão das iniciativas, da ação docente, é necessária perante o real vivido, pois englobam os sentimentos pessoais e coletivos. $\mathrm{O}$ julgar é aberto e questiona as singularidades e humanidades, envolvendo sentimentos de pertencimento, de sentidos e significados edificantes do ser humano que habita o mundo. Um acordo, para a definição dos saberes para a dinâmica da vida, está intrínseco na experiência estética, em processos criativos.

[...] a tarefa de sensibilizar e desenvolver os sentidos, fazendo-se acompanhar de uma visão criticamente filosófica de seu papel na obtenção do saber, compete prioritariamente aos nossos cursos de formação de professores, às licenciaturas levadas a efeito no âmbito do 
ensino superior. Uma tarefa, sem dúvida, difícil e árdua, pelo comprometimento atual de tais instituiçóes com a mentalidade instrumental e utilitária estabelecida pelo mercado. (DUARTE JUNIOR, 2000, p. 213).

As práticas coletivas realizadas buscaram ressignificar os aspectos do humanescer na docência ao promover açóes pedagógicas que valorizam a atuação docente. Para a discente (8) "O enfoque desta proposta de ensino transformador, vem contribuindo a cada dia e já proporcionou grande conhecimento para nós acadêmicos, com uma nova visão de ensinar, pautados na diversidade cultural, na solidariedade, na afetividade, no amor, no sentir, principalmente com um olhar mais humanizador, pensando principalmente no outro". Os estudos efetivos foram atos de reflexão e envolvimento coerente com o potencial humano de ser e aprender, em que as experiências estéticas ampliaram os afetamentos.

As experiências estéticas promovem a abertura de consciência de si, do outro e do mundo na sensibilidade e construção de conceitos, valorizando saberes presentes no mundo vivido e que potencializam o desenvolvimento humano. As aprendizagens dos discentes foram promovidas valorizando diferentes manifestaçóes humanas e as aprendizagens pessoais, enriquecidas com as práticas expressivas na poesia, teatro, música, criação coreográfica com diferentes recursos e ambientes sensibilizadores. Tornou a diversidade e interculturalidade muito presentes, com todo o cuidado em torno das diferenças e equidade.

Foi possível identificar no relatório da discente (3) a expressão de suas percepçóes, após a realização das práticas "Que ótimo reunir diversas propostas na ação solidária que é a extensão, me senti mais cidadão e humana. Ajudamos as pessoas a cultivar os alimentos, expressar sentimentos com a arte, com a dança". $\mathrm{Na}$ sensibilização e entendimento, o corpo ampliado em sua consciência foi envolvido na dinâmica da construção de conhecimento, que para Morin (2000, p. 76),

[...] é necessário aprender a "estar aqui" no planeta. Aprender a estar aqui significa: aprender a viver, a dividir, a comunicar, a comungar; é o que se aprende somente nas - e por meio de - culturas singulares. Precisamos doravante aprender a ser, viver, dividir e comunicar como humanos do planeta Terra, não mais somente pertencer a uma cultura, mas também ser terrenos. Devemo-nos dedicar não só a dominar, mas a condicionar, melhorar, compreender. 
$\mathrm{Na}$ compreensão os acadêmicos expressaram as mudanças necessárias, propondo açóes efetivas em uma "consciência cívica terrena" proposta por Morin (2000), de responsabilidade e da solidariedade. "Uma questão importante que não pode ser deixada de lado é a interação, o contato e aprendizado com a terra, com nossos futuros colegas, com a comunidade. Em cada uma dessas interaçôes, saimos com algo a mais, [...] aumentamos a nossa condição de reflexóes sobre as diversas formas de viver e de cidadania". (Discente 7).

As açóes tornaram-se oportunidades de compartilhamento de conhecimentos e envolvimento dinâmico entre os discentes, com efetiva construção dos saberes humanizados, fortalecendo uma cultura para a vida e relaçôes afetivas positivas. As manifestaçôes culturais de diferentes origens e etnias interligaram aspectos pessoais e coletivos, favorecendo as relaçóes de pertencimento social.

\section{Consideraçóes Finais}

$\mathrm{Na}$ docência as experiências estéticas possibilitaram aprendizagens atreladas a expressividade e criatividade do ser humano no seu sentir, pensar, agir e conviver envolvido no humanescer que integra o respeito e defesa à vida. O envolvimento do humano é dinâmico em sua consciência complexa, da tessitura do real emaranhada na cultura contextual. Os valores presentes na consolidação da prática foram fundamentais na sensibilização que possibilitou a percepção de si, do outro e do meio em sua singularidade, favorecendo os princípios de justiça social.

O envolvimento com diferentes instituiçóes e sujeitos em suas diversidades, possibilitou a prática estética em que os processos sociais, culturais e criativos impulsionaram o ser humano ao sublime no sentido da justiça social. Foi possível ampliar a corresponsabilidade e solidariedade no envolvimento entre pessoas, saberes, natureza e o transcendente.

Este processo é no tempo e no espaço da docência profundamente educativo para o humanescer do docente em formação, tendo em vista aprendizagens comprometidas com a justiça social. $O$ envolvimento na condição de uma docência que prioriza a experiência estética colabora com o humanescer na existência e possibilita de conexão com o eu e com o outro nos saberes e conquistas sociais.

Diante do exposto, ser discente na jornada acadêmica de formação dentro de uma docência de experiências estéticas certamente pode possibilitar descobertas de conhecimentos criativos e coerentes com o ser sensível- 
inteligível nas suas subjetividades, e esse é caminho para um humanescer com força criativa para uma postura de justição social no desenvolvimento de uma cidadania saudável.

\section{Referências}

ALVES, Rubem. A alegria de ensinar. $3^{\text {a }}$ edição, ARS Poética Editora ltda, 1994.

ARISTÓTELES. Ética a Nicômaco. In: Coleção aos Pensadores. São Paulo: Nova Cultural Ltda. 1996.

BRASIL. Conselho Nacional de Educação. Parecer CNE/CP no 2/2019. Diretrizes Curriculares Nacionais para a formação inicial em nível superior (cursos de licenciatura, cursos de formação pedagógica para graduados e cursos de segunda licenciatura) e para a formação continuada. Brasília: 2019.

- Lei de Diretrizes e Bases da Educação Nacional, LDBEN. 9394/1996. Brasília: 1996.

BAUMGARTEN, Alexander Gottlieb. Estética: a lógica da arte e do poema. Tradução Miriam Sutter Medeiros. Rio de Janeiro: Vozes, 1993.

DITTRICH, Maria Glória; RAMOS, Flávio. Um olhar transdisciplinar sobre a formação universitária: desafios para humanescer na saúde Revista Plurais Virtual, Anápolis -Go, Vol.7, n. 1 - Jan./Jun. 2017 - p. 114-130.

DITTRICH, Maria Glória; URIARTE NETO, Mario. Humanescer na saúde. Um olhar sobre a formação universitária. In FARHAT, Eleide Margarethe Pereira; DITTRICH, Maria Glória. Educação e saúde. Políticas Públicas e vivências dialógicas. Itajaí: Editora da UNIVALI, 2016.

DUARTE JR, João Francisco. O sentido dos sentidos: a educação do sensivel. Tese de Doutorado Universidade Estadual de Campinas UNICAMP. São Paulo: 2000.

FRANCO, Cezar Augusto de Oliveira. Direitos indígenas e mobilização: um olhar sobre a triplice fronteira - Brasil, Guyana e Venezuela. 2012. xii, 188 f., il. Tese (Doutorado em Relaçôes Internacionais e Desenvolvimento Regional) 
- Programa de Doutorado Interinstitucional em Relaçóes Internacionais e Desenvolvimento Regional, Universidade de Brasília/UFRR/FLACSO, Brasília, 2012.

HERMANN, Nadja. O enlace entre corpo, ética e estética. Revista Brasileira de Educação, v. 23 e230051, 2018.

Ética e estética: a relação quase esquecida/ Nadja Hermann. - Porto Alegre: EDIPUCRS, 2005

KANT, I. Crítica da Faculdade do Juizo. 2. ed. Tradução Valério Rohden e Antônio Marques. Rio de Janeiro: Forense Universitária, 2005. . A crítica da razão pura. São Paulo: Editora Martin Claret, 2002.

MATURANA, H.; VARELA, F. A árvore do conhecimento. As bases biológicas do entendimento humano. Campinas: Psy II, 1995.

MERLEAU-PONTY, Maurice. Fenomenologia da percepção (C. Moura, Trad.). São Paulo: Martins Fontes, 1999.

MORAES, M. C. Saberes para uma cidadania planetária. In UNESCO, Governo do estado do Pará, UECE e UCB, Fortaleza, 2016. Disponível em http://aprece.org.br/wp-content/uploads/2016/03/CidadaniaPlanet\%C3\%A1ria.pdf Acesso em 10/07/2020.

- Transdisciplinaridade, criatividade e educação. Fundamentos ontológicos e epistemológicos. Campinas: Papirus, 2015.

MORIN, Edgar. Os setes saberes necessários à educação do futuro. Tradução de Catarina Eleonora F. Silva e Jeanne Sawaya. São Paulo: Cortez, 2000.

SHILLER, J.C.F. Über die objektiven Bedigungen der Shönheit. In BARBOZA, Jair. Infinitude subjetiva e estética. Natureza e arte em Schelling e Shopenhauer. São Paulo: UNESP, 2005.

SUANNO, Marilza Vanessa Rosa; MORAES, Maria Cândida. Breve apontamento sobre ensino e pesquisa em didática no Brasil. In REIS, Marlene Barbosa de Freitas; LUTERMAN, Luana Alves. Interdisciplinaridade na educação. Redimensionando práticas pedagógicas. Anápolis: Editora UEG, 2017.

TORRE, S. de la. Transdisciplinaridade e ecoformação. São Paulo: Triom, 2008. 
UNESCO. Declaração Mundial sobre Educação para Todos: satisfação das necessidades básicas de aprendizagem. UNESCO: Jomtien, 1990.

Recebido em: 25 ago. 2020

Aceito em: 06 dez. 2020 